\title{
Application of Integrated Geophysical Technologies to the Exploration of Polymetal Deposits: Case study in Fufang, Jiangxi, China
}

\author{
Shuo Wang ${ }^{1, *}$, Hu Liu ${ }^{1}$, Huaiyang Li ${ }^{1}$, Shuxin Duan ${ }^{1}$ and Yue $\mathrm{Zhu}^{2}$ \\ ${ }^{1}$ Beijing Research Institute of Uranium Geology, Beijing100029, China \\ ${ }^{2}$ Department of Geology and Geophysics, University of Utah, Salt Lake City, UT 84112, USA
}

Received 17 May 2019; Accepted 29 July 2019

\begin{abstract}
Prior research has confirmed that the Fufang prospecting area exhibits good mineral anomalies. The geochemical anomaly that pertained to copper content was delineated within a wide range; hence, the deployment of boreholes and trenches was hindered for further prospecting work. To shrink this anomaly range and identify favourable areas for mineralization, a combination of geophysical methods based on electrical and magnetic theories was proposed. First, magnetic and induced polarization (IP) mappings were utilized to characterize the distribution of anomalies horizontally. Then, the major structures were identified using IP and audio magnetotelluric sounding measurements. The integrated geophysical anomalies with good spatial consistency were also delineated. Results demonstrate that the main strike of the regional fault is in the direction of $\mathrm{NE} 50^{\circ}$, and some parallel secondary faults are also inferred. The dykes in this area are well developed in the strata due to rock mass intrusion. Several geophysical anomalies are highly superposed. This condition indicates good prospecting of copper and polymetals. The found anomalies delineate a new prospecting area that is $62 \%$ smaller than the previous one. This study provides a good prospect in the designated anomaly area.
\end{abstract}

Keywords: Audio Magnetotelluric, Integrated Geophysical Prospecting, Copper and Polymetals, Fufang Rock Mass

\section{Introduction}

Polymetal deposits with hydrothermal property are mostly located near areas with active magmation. Such areas contain several faults, hydrothermal alterations, and metal sulfides [1]. During exploration, the prospecting depth is gradually changed to the space of hundreds meters [2]. The areas are difficult to break through in the deep when using sampling and trenching on the surface only. Geophysical technology is an effective method for detecting media underground. Moreover, the development of integrated inversion enhances the veracity of geophysical results. Some geophysical explorations in a mountain area are influenced given its topographic condition. Thus, in complex terrain areas, integrated geophysical exploration should delineate magmatite, identify the occurrence of faults related to metallogeny, locate metal sulfides, and shrink the prospecting range. This study is consequential for polymetal prospecting.

Considering the issues to be resolved, geophysical exploration technologies were used to detect metal sulfide concentration, and ascertain the information regarding underground media [3-6]. Given the rough terrain, heavy vegetation, and bad traffic condition, geophysical methods that require large instruments are inapplicable. Meanwhile, the complexity and gradual variation of lithology, caused by the intrusion, result in difficulties in geophysical interpretation. Laterally shrinking the target prospecting area and detecting the concealed structures in its depth entail considerable challenges.

*E-mail address: spoonmiller@126.com

ISSN: 1791-2377 @ 2019 School of Science, IHU. All rights reserved.

doi:10.25103/iestr.124.09
In consideration of the aforementioned conditions, induced polarization (IP), audio magnetotelluric (AMT), and magnetic methods are utilized as portable instruments and effective measures for detecting targets in this area. During measurement, mappings were initially conducted to laterally characterize anomalies. Then, sounding profiles are deployed at the key section. Lastly, the favorable mineralization section is delineated after obtaining the overall distribution of physical properties.

\section{State of the Art}

Geophysical techniques represent primary methods for prospecting and exploration. IP, AMT, and magnetic explorations are effective in detecting polymetal concentrations, concealed faults, and lithology. Arifin [7] applied the IP method to acquire a 3D model of resistivity and chargeability in a gold mineralization area. The rough strike and depth of the mineralization belt were delineated and the anomaly section with low resistivity and high chargeability was considered a prospective area. Tkachev A. V. [8] conducted IP soundings to identify the metasomatic belt of carbon in a gold deposit. Only an metallogenic environment was detected in relation to gold without identifying the mineralization concentration. Ogawa. Y [9] conducted an AMT survey. Then, the location and depth of concealed faults were deduced using the survey results and information in the deep for delineating the target of the related metallogeny was provided. Liu $\mathrm{H}$. [10] implemented AMT soundings to identify faults related to uranium mineralization. Buried structures were detected, and the environment of structures was characterized in relation to 
metallogeny. However, the interpretation of anomalies using a single method may be uncertain because geophysical interpretation is indeterminate. Hence, a better result may be acquired using integrated geophysical methods through constraint and verification among different methods. A ground penetrating radar and a seismic method was utilized by Ivanov [11] in a permafrost area. The approach was proven to be effective in detecting the range of melted soil on a railway. However, this combination is unsuitable for metal exploration. Caikun GAO [12-13] implemented an integrated interpretation of geophysical methods to enhance their reliability. However, this study did not mention prospecting exploration. Saeed K. A. [14] applied magnetic, direct current, and IP methods in Halab Dandi. The results were proven similar, with high reliability, and a good proposal was provided for a further drilling program. He Chunyan [15] and Guo Guoqiang [16] applied controlled source AMT, transient electromagnetic, and spectrum IP methods to detect the metallogenic environment of gold, copper, and polymetals. The results provided information from the deep for the deployment of boreholes. However, the instruments required for these methods are too heavy to use in an area with a highly complex terrain.

One or several technologies have been used in the preceding studies. The comparison of anomalies from different methods may reduce the unavoidable nondeterminacy of geophysical methods. Several combinations of existing technologies are too cumbersome to use for measuring, and others are unsuitable for metal exploration. The current study uses a combination of mapping and sounding. First, magnetic and IP mappings are conducted to laterally characterize the distribution of anomalies and delineate the structures of ore formations and mineralization concentration. Then, IP and AMT sounding measurements are performed for the occurrences of structures and anomalies in the deep. Lastly, the results are provided and analyzed to propose locations for drilling and trenching.

The remainder of this study is organized as follows. Section 3 briefly introduces geophysical technologies, including the information of instruments, data acquisition, and processing. Section 4 discusses the integrated geophysical anomalies combined with geological information. The distribution of strata, faults, and magmatite are inferred and the favorable area is also delineated in this section. Section 5 provides the conclusions drawn from this study

\section{Methodology}

This study used magnetic, IP, and AMT methods. Magnetic and IP mappings with an azimuth of northwest-southeast were deployed in accordance with the distribution of water sediments and the features of strikes in rock masses, dykes, and faults. Subsequently, four AMT and one IP sounding profiles (LY1-LY4) were measured on the basis of the anomalies and favorable information. The mapping scale was 1:10000, and mapping was conducted with a grid of 100 $\mathrm{m} \times 20 \mathrm{~m}$. The site spacing of the sounding profiles was 20 $\mathrm{m}$ with a direction of $145^{\circ}$ southeast.

\subsection{AMT method}

AMT sounding is based on the magnetotelluric (MT) sounding method. The two methods are nearly the same in theory but differ in their acquisition band. The MT method can detect the electric structure underground up to hundreds of kilometers beneath. MT has become one of the most efficient methods after decades of development.

The V8 multi-EM system and the AMTC-30 sensor were used in this AMT survey. To obtain the target depth of $1 \mathrm{~km}$ in the resistance area in accordance with the equations for skin depth (Equation 1) and exploration depth [17] (Equation 2 ), the high-frequency data fully fitted the exploration depth requirement and stainless electrodes were used for convenient measurement. The electrodes were set using the electromagnetic array profiling method [18], and thus the influence of static shift was eliminated. A sensor-sharing technology was also utilized (Fig. 1). A master box was set with four channels (Ex, Ey, Hx, and Hy), and several auxiliary boxes were located at neighboring sites for the telluric signal. This approach is a good means to enhance efficiency. After data acquisition, regular processes were conducted. The first step was fast Fourier transform, followed by the estimation of the impedance tensor, and the reading of the cross-power spectrum. Lastly, 2D inversion based on the regularization algorithm was implemented. Further works, such as gridding, plotting the geological interpretation sections, and inferring the occurrence of the measured or concealed faults, followed.

$$
\begin{aligned}
& \delta=\sqrt{\frac{2}{\omega \mu \sigma}} \approx 503 \sqrt{\frac{\rho}{f}} \\
& D=\frac{\delta}{\sqrt{2}} \approx 356 \sqrt{\frac{\rho}{f}}
\end{aligned}
$$

where $\delta$ is the skin depth, $D$ is the exploration depth, $\rho$ is the equivalent resistivity, $\sigma$ is the equivalent conductivity, $f$ is the lowest frequency of the acquired data, $\omega$ is the angular frequency, and $\mu$ is the dielectric constant in vacuo.

\subsection{IP method}

The IP method is a widely applied geophysical technique. The rectangular wave current of a bidirectional pulse is sent to the study area with a specific array. The receivers measure the feedback of the secondary voltage induced by lithology and mineralization. The primary field reflects conductivity and the secondary voltage leads to polarizability. The foremost application of the IP method is to detect the mineralization of pyrite, graphite, magnetite, or other polymetals with sulfide.

The central gradient and Schlumberger arrays were adopted respectively for the mapping and sounding measurements. A system that included WDJS-2 receivers and a WDFZ-10A transmitter was utilized (Fig. 2). A knapsack generator with a maximum power of $3 \mathrm{KW}$ was used due to the terrain and traffic condition.

Overall, the lithology in the study area presented high resistivity. Therefore, the acquisition parameters were set accordingly. To provide sufficient charging time and record the signal before it rapidly decreases, the transmission period was set as $16 \mathrm{~s}$ with a delaying time of $100 \mathrm{~ms}$. Resistivity was calculated through the coefficient of the array, and polarizability was computed using Equation 3 . Then, the resistivity and polarizability data were gridded and plotted onto contour maps and sections. Lastly, the strike of the faults and the concentration of the metal sulfide were 
delineated through the integrated analysis of the anomalies and geological information.

$$
\eta=\frac{U_{2}}{U_{0}} \times 100 \%
$$

where $U_{0}$ is the voltage of the primary field when the current is supplied, and $U_{2}$ is the voltage of the secondary field when the current is off. $\eta$ denotes the polarizability of lithology.

\subsection{Magnetic method}

A magnetic survey is based on the magnetic variation of different lithology. Magnetic fields with certain characteristics are formed due to such difference and are superimposed on the normal magnetic field generated by the Earth as magnetic anomalies. By measuring and analyzing these magnetic anomalies, the relationship between them and the geological structure is studied. In addition, relevant conclusions from underground and mineral distribution are plotted.

The magnetic meters of GSM-19W were used in this magnetic survey as produced by GEM. To measure a single mode, readings were recorded repetitively at each point until the reading became stable and the variation was less than 1
nT. This value of the total magnetic field was evaluated as reliable.

After data acquisition, duration correction was implemented using Equation 4 by referencing the recording data and base point readings. Then, normal field correction was calculated on the basis of the Gaussian coefficient provided by the model of the International Geomagnetic Reference Field 2010.0. Given that the influence of oblique magnetization changes with different latitudes, the characteristics of magnetic anomalies change in different areas with the same magnetic body. To integrate the principle of interpretation, the concept of reduction-to-thepole (RTP) was adopted to unify the direction of magnetization. This approach transforms oblique magnetization into a vertical direction and simplifies the anomaly. To obtain the strike of the deep structure, upcontinuation was accomplished to prevent the magnetic anomalies from being submerged by inhomogeneous bodies near the surface. Lastly, the processed magnetic data were gridded and the primary faults with large scales were deduced laterally.

$$
F_{T}=F_{\mathrm{o}}-\Delta F_{\mathrm{d}}
$$

where $F_{T}$ is the magnetic value after the duration correction, $F_{\mathrm{o}}$ is the original readings at each point, and $\Delta F_{\mathrm{d}}$ is the value of the duration correction.

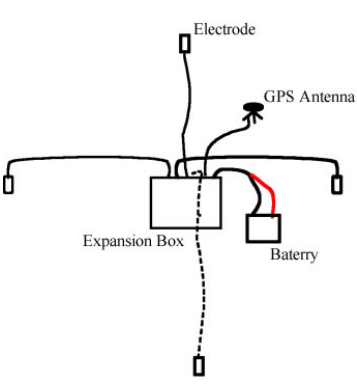

Fig. 1. Shared magnetic signal in AMT measurement
4 Result Analysis and Discussion

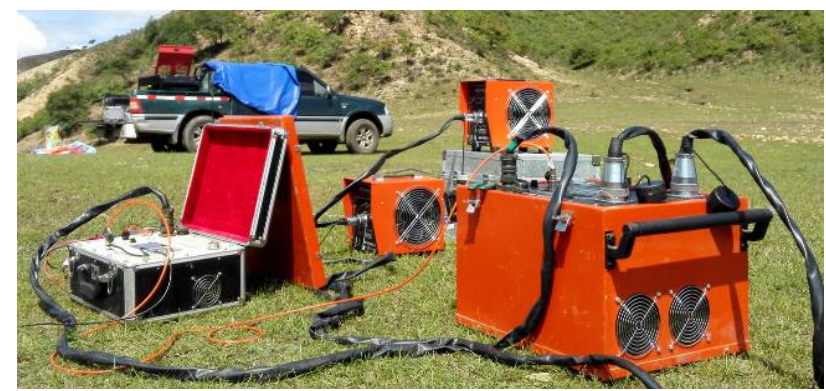

Fig. 2. Transmitting system, model WDFZ-10A

The location and occurrence of faults is generally inferred in accordance with the lateral discontinuity or saltation of resistivity from AMT inversed sections. A total of 29 faults were inferred from 4 sections, and 13 of these were measured faults. The result of the IP mapping indicated 4 faults based on banded or bead-like anomalies. One of the faults is a measured fault. Following the same principle, the saltation of the magnetic field in the study area indicates a single fault.
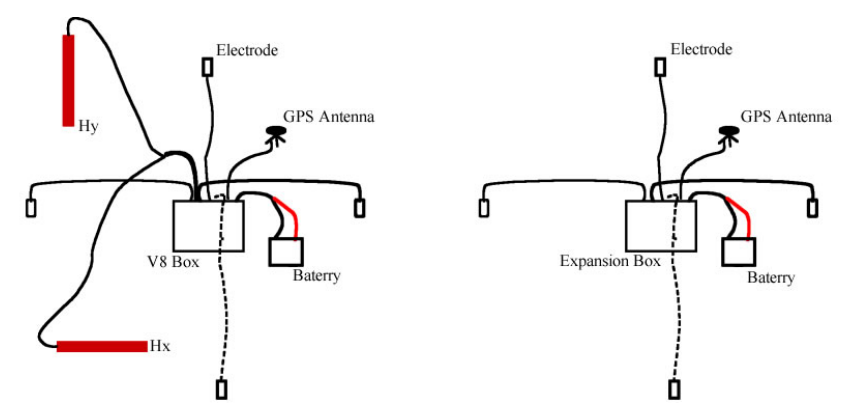

After analyzing the previous and current achievements of geology, geochemistry, and geophysics, the occurrence of the wall rock was delineated in the deep. The concealed faults were deduced, and the geophysical anomalies were located (Figs. 3 and 4). Then, favorable areas were delineated. The inferred faults in the AMT sections (Figs. 59) were deduced to extend on both sides and then connect with each other. The IP and magnetic mapping results were regarded as evidence of constraint and correction on the basis of structure ichnography. Consequently, several assumptions were made.

Overall, the resistance characteristic of the wall rock in the study area includes two layers from low to high resistivity. The low-resistivity layer near the surface is generally as thick as dozens to a hundred meters. This range is inferred as the result of weathering. The lithology of this layer is determined as medium and fine granite in accordance with the geological cognition and sampling from outcrops. The second layer with high resistivity is regarded as a relatively steady stratum. High resistivity is commonly developed in this layer, and thus it is considered the strata of $\mathrm{Z1}, \mathrm{Z2}$. The lithology mostly comprises acidic igneous rocks, such as medium and fine granite and diorite. The depth of the second layer extends down over $1 \mathrm{~km}$. No other layer is 
present in the resistivity sections, and no other overlying section is deduced. However, only the southernmost part of the LY1 section exhibits a remarkable difference. The resistance characteristic in this section is evidently lower than that in other parts. Compared with the other areas, elevation is higher and regarded as an uplift. That is, the low resistivity layer at the bottom is presented as a type of metamorphic rock with low resistivity, such as phyllite.

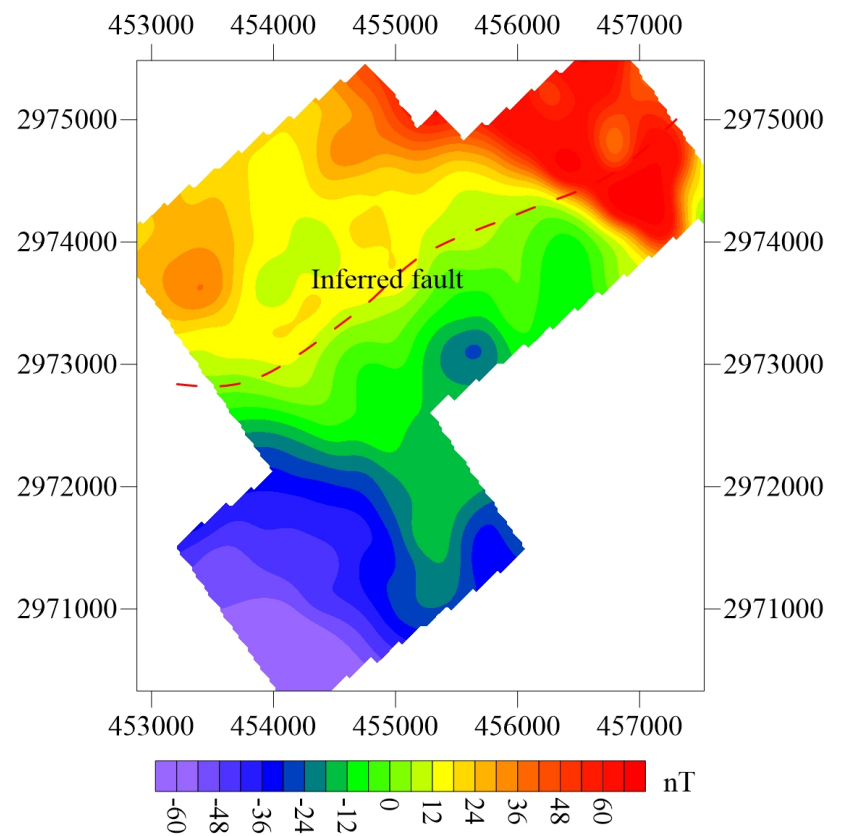

The AMT and IP results indicate a fault with a strike in the northeast, which is located near Huangsha Village. This finding is highly consistent with the geological information. The AMT results indicate that a dyke of quartz porphyry developed in the north of Huangsha Village along a series of secondary faults near a measured structure. We can infer from the location that this fault is the same as that in the northwest of Huangsha Village.

After the integrated analysis of geological anomalies; magnetic, AMT, and IP explorations; and the boundary of geochemical anomalies, the regional deep fault can be inferred in the middle of the study area, with a strike in the northeast. In the regional analysis, the Zhukeng deposit in the west, the largest dyke of quartz porphyry, and the anomalies of polarizability are distributed near this fault. Therefore, this fault is a significant structure related to mineralizing in this area.

In the south of the study area, the largest anomaly of polarizability overlaps with the dykes of quartz porphyry and faults are inferred by AMT. This anomaly is deduced to have developed near a fault in the east-west direction. Although the extent to the deep is not substantial, the scale in the strike direction is considerable. The high anomaly of polarizability is commonly induced by metal sulfide concentration. This phenomenon indicates the close relationship between mineralization and the structures in this area.

Fig. 3. Magnetic contour map after RTP and up-continuation of $200 \mathrm{~m}$

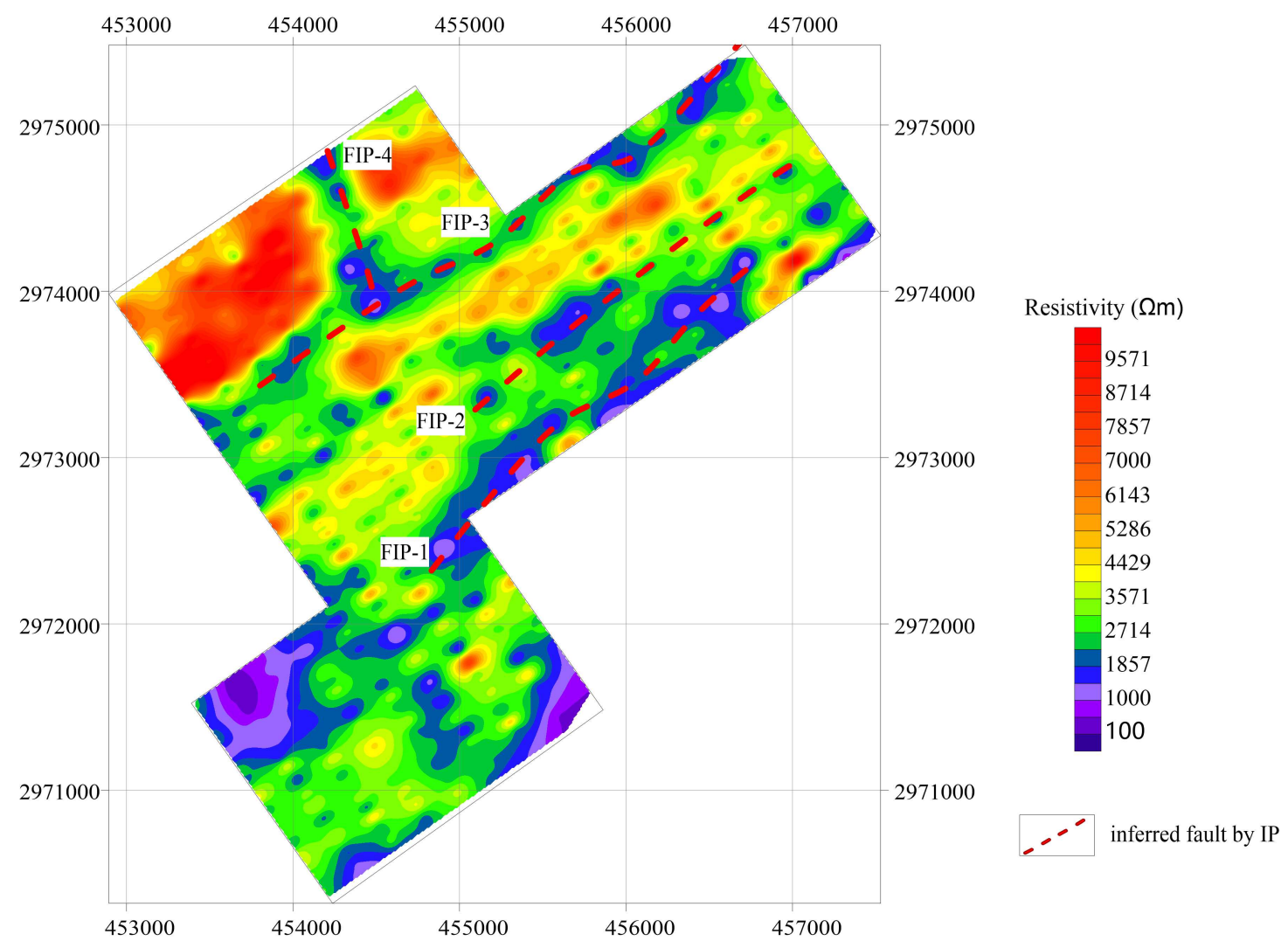

(a) 


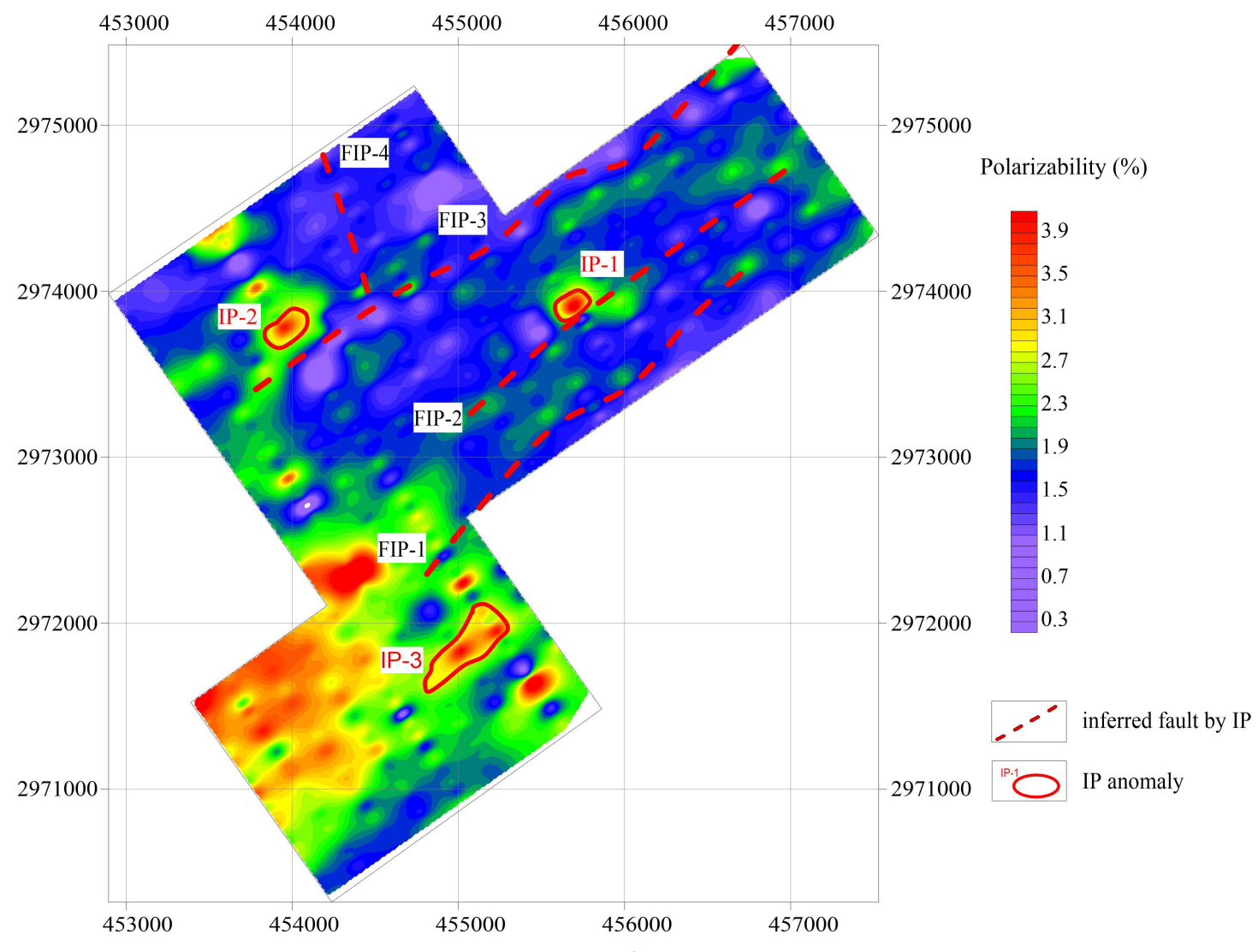

(b)

Fig. 4. Contour map of apparent resistivity and polarizability (a) Resistivity contour map (b) Polarizability contour map
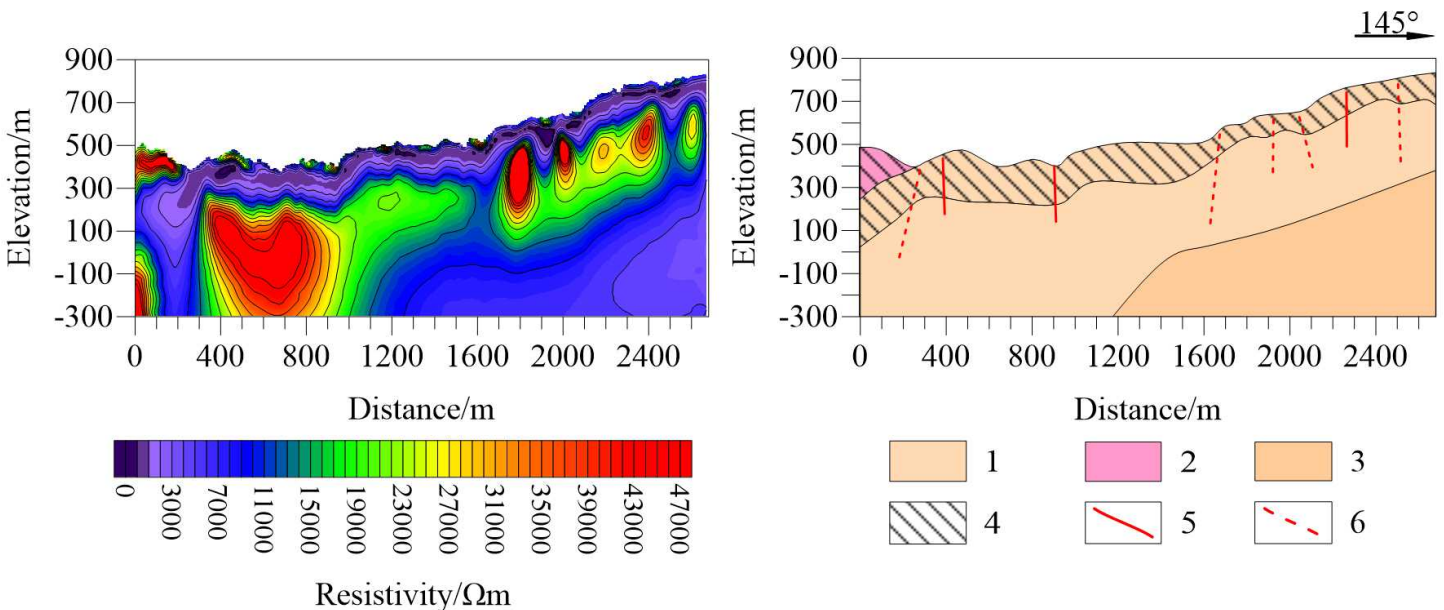

Fig. 5. Resistivity contour map and geological interpretation section of the LY1 line

1- syenite, diorite; 2- granite; 3- metamorphic rocks; 4- weathered layer; 5- measured fault; 6- inferred fault. 

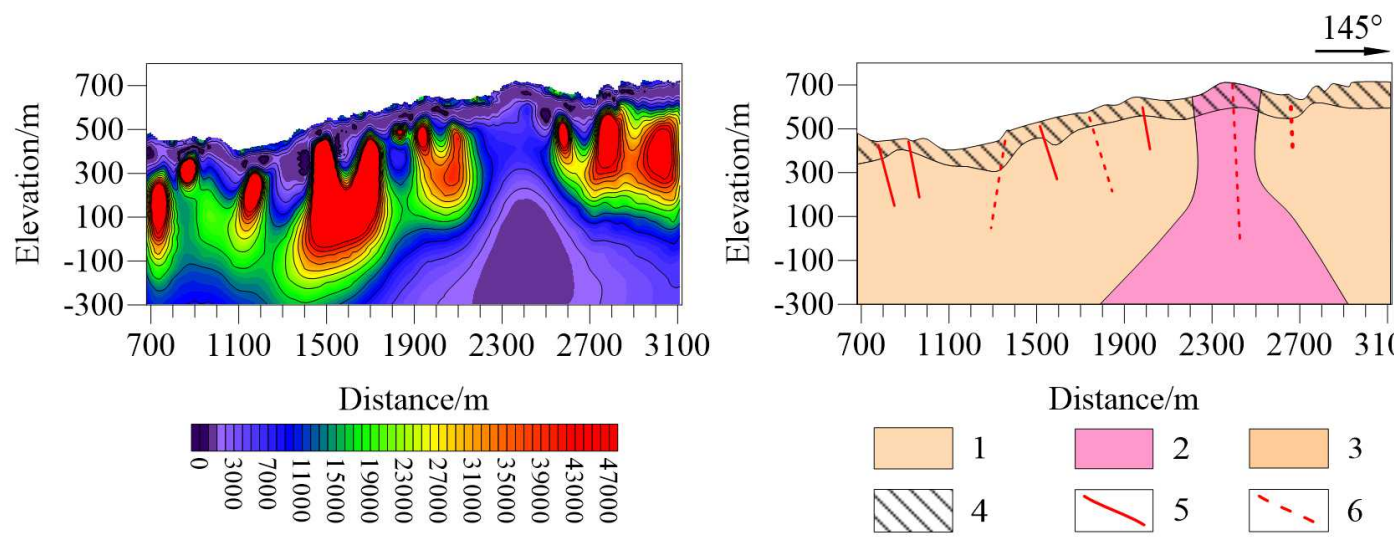

Resistivity/ $\Omega$.m

Fig. 6. Resistivity contour map and geological interpretation section of the LY2 line

1- syenite, diorite; 2- granite; 3- metamorphic rocks; 4- weathered layer; 5- measured fault; 6- inferred fault.

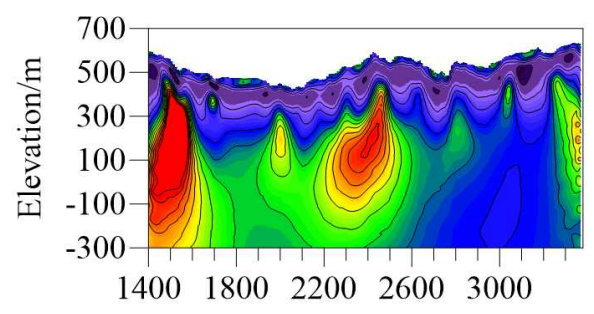

Distance $/ \mathrm{m}$

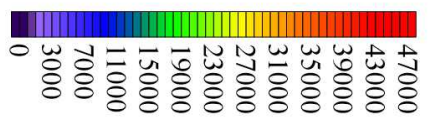

Resistivity $/ \Omega m$

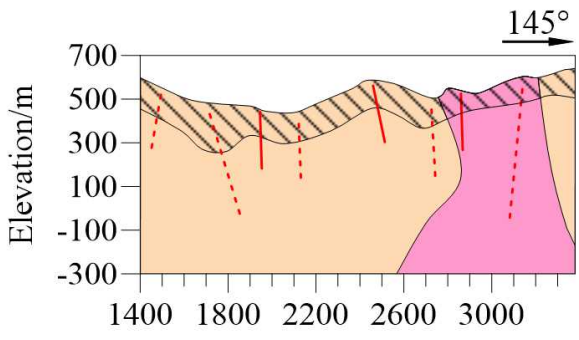

Distance/m

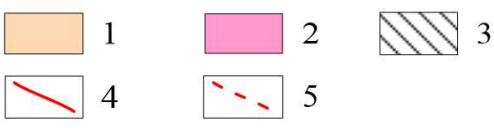

Fig. 7. Resistivity contour map and geological interpretation section of the LY3 line

1- syenite, diorite; 2- granite; 3- weathered layer; 4- measured fault; 5- inferred fault.

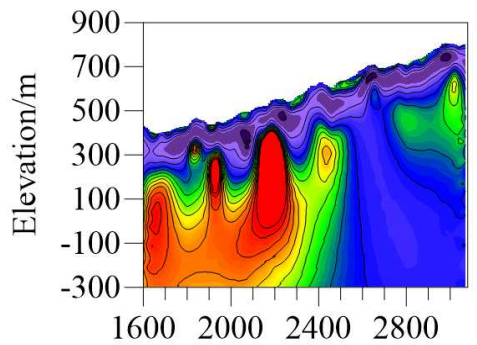

Distance/m

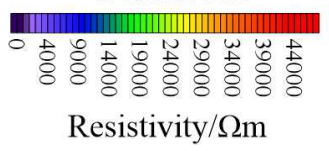

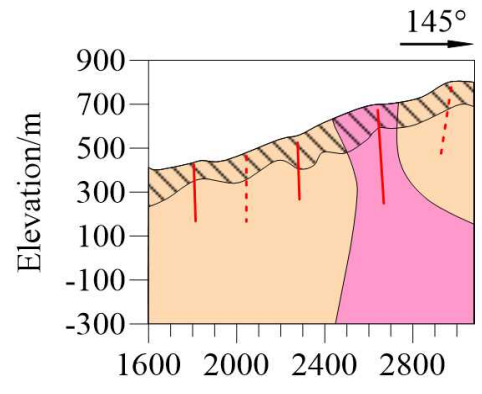

Distance/m

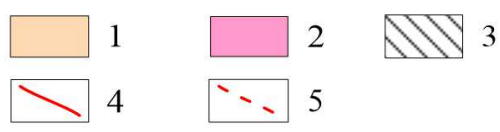

Fig. 8. Resistivity contour map and geological interpretation section of the LY4 line 


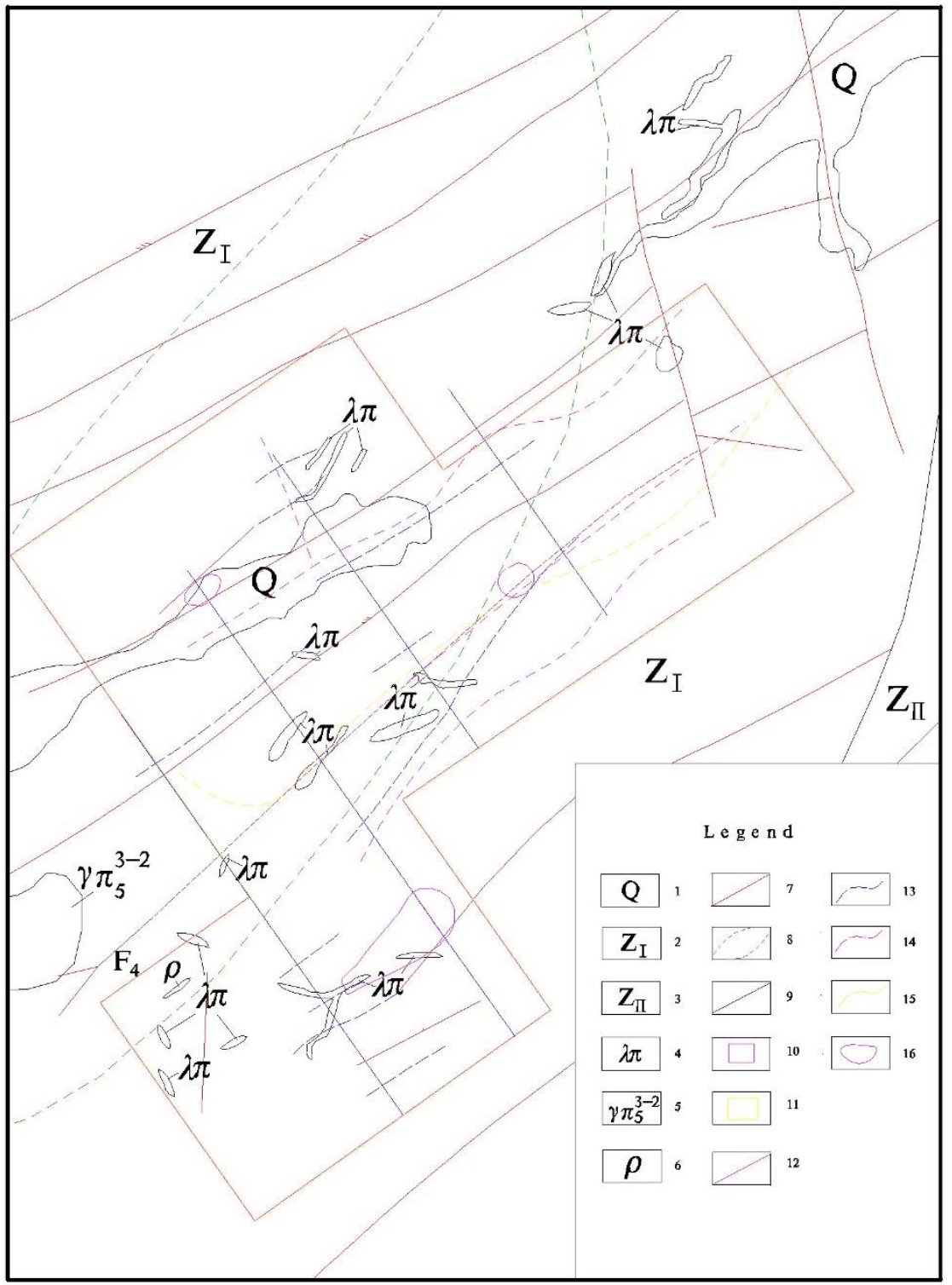

Fig. 5. Integrated interpretation map of geology and geophysics

1-Quaternary; 2-Lower Cathay; 3-Middle Cathay; 4-Quartz Porphyry; 5-Yanshanian Granite; 6-Pegmatite; 7-Fault; 8-Copper Anomaly of Stream Sediment; 9-AMT Line; 10-IP Mapping; 11-Magnetic Mapping; 12-IP Sounding Line; 13-AMT Inferred Fault; 14-IP Inferred Fault; 15-Magnetic Inferred Fault; 16-IP anomaly

\section{Conclusions}

To delineate the favorable area and obtain the geophysical anomalies in the deep and in relation to metallogeny, integrated geophysical methods were conducted in accordance with electrical and magnetic theories. The characteristics of the primary anomalies were acquired. Then, sounding measurement was performed to dissect the scale of the anomalies in the deep. The analysis of existing geological and geochemical information delineated several concealed faults and three concentration belts of mineralization. Lastly, the following conclusions could be drawn.

(1) The anomalies of geophysical and geochemical measurements are coincident on the plane. In general, the trend of physical properties gradually varies from southwest to northeast. Thus, the Zhukeng rock mass exhibits hydrothermal modification and the influence grade decreases as the distance to the rock mass increases. As deduced from the IP anomalies, the metallogeny is closely related to the faults and rock mass. Thus, the faults and dykes near the rock mass represent the most promising prospecting target of the geological body in the subsequent exploration of this area.

(2) Four geophysical methods were implemented in the Fufang area. Magnetic and IP mappings were conducted to identify the lithology, distribution of structures, and delineation of metal sulfide using a full-scale, efficient measurement. Then, combined with the geological achievement, AMT and IP sounding profiles were deployed at the key section and were focused on the occurrences of anomalies in the deep, lithology, faults, and other underground structures.

The acquired geophysical data and existing geological information were analyzed integrally. As the distribution of structures and geophysical anomalies were ascertained further, the range of the prospecting area shrank and information about the deep was provided for succeeding explorations. The lack of information about boreholes causes difficulties in geophysical interpretation. Hence, the verification of the drilling program should be enhanced in the next stage of exploration. Then, combined with the borehole and geophysical results, the geological 
environment and metallogeny in this area can be examined further.

\section{Acknowledgements}

This work was supported by "Long Can" Scientific Research Project (Phase II) of China National Nuclear Corporation (Grant No. 2018-111).
This is an Open Access article distributed under the terms of the Creative Commons Attribution License

\section{References}

1. Chen S. Z., Ma M., Chen G., et al., "Taoxi uplift of wuyi metallogenic belt, its tectonics, magmatism and metallogeny". Earth Science (Journal of China University of Geosciences), 23(2), 2010, pp.969-984 (in Chinese).

2. Liu C. Z., Yin W. Q., Zhang J., et al., "Ore-controlling factors and prospecting prediction criteria of the $\mathrm{Sn}-\mathrm{Cu}$ polymetallic deposit in Wuyishan metallogenic zone". Mineral Resources and Geology, 35(6), 2009, pp.124-128 (in Chinese).

3. ZHANG R., "The study on application of the audio frequency magnetotelluric method in Azelik area of Niger". Acta Geologica Sinica (English Edition), 88(s2), 2014, pp.1428-1429.

4. Xiao Q., Cai X., Liang G., et al., "Application of 2D magnetotelluric methods in a geological complex area, Xinjiang, China". Journal of Applied Geophysics, 75(1), 2011, pp.19-30.

5. Ferdows M. S., Ramazi. H. R., "Application of the singularity mapping technique to identify local anomalies by polarization data (a case study: Hamyj copper deposit, Iran)". Acta Geodaetica et Geophysica, 50(3), 2015, pp.365-374.

6. Elwaheidi M, Ghrefat H A, Batayneh A, et al., "Integrated application of geoelectrical techniques for structural investigations: case study of Wadi Marsad Graben, Jordan". Arabian Journal of Geosciences, 9(6), 2016, pp.435.

7. Arifin M., Kayode J., Khairel I., et al., "Data for the potential gold mineralization mapping with the applications of electrical resistivity imaging and induced polarization geophysical surveys". Data in Brief, 22, 2019, pp.830-835.

8. Tkachev A. V., Khasanov I. M., Mikhalitsyna T. I., "Geological and geophysical interpretation of induced-polarization data on gold depoits in the Yana-Kolyma orogenic belt". Russian Geology and Geophysics, 58(11), 2017, pp.1426-1434.

9. Ogawa Y., Uyeshima M., Honkura Y., et al., "Audio-frequency magnetotelluric imaging of an active strike-slip fault". Earth Planets \& Space, 46(5), 1994, pp.403-408.
10. Liu H., Duan S. X., Wang S., et al., "The application effect of AMT and high precision magnetic method in identifying the key ore controlling factors in Xiangshan uranium ore field". Uranium Geology, 31(s1), 2015, pp.308-314 (in Chinese).

11. Ivanov, Klepikova, Shkobokov, et al., "Integrated geophysical surveys on railroads in permafrost areas". Sciences in Cold and Arid Regions, 5(5), 2013, pp.582-586."

12. Gao C. K., Du H. K., Tang J. T., et al., "Application of integrated geophysical interpretation on accumulation body". Global Geology (English Version), 11(3), 2008, pp.191-196.

13. Gao C. K., Xiao C. A., Du A. M., et al., "Application of integrated geophysical methods on Dian Chi water supplement project". Progress in Geophysics, 26(4), 2011, pp.1440-1447.

14. Kazem A. S., Norouzi G., Ardejani F., et al., "Application of magnetometery, electrical resistivity and induced polarization for exploration of polymetal deposits, a case study: Halab Dandi, Zanjan". In: 2nd International Conference on Advnces in Engineering Sciences and Applied Mathematics, Istanbul, Turkey: ICAESAM, 2014.

15. He C. Y., Guo P., Guo G. Q., "Application of comprehensive geophysical prospecting in Yuantuan area in northwestern Zhaoyuan City in Shandong Province". Shandong Land and Resources, 33(12), 2017, pp.49-54 (in Chinese).

16. Guo G. Q., "Application of comprehensive geophysical prospecting in huh sala copper and poly-metal deposit in alxa left banner in Inner Mongolia Autonomous Region". Shandong Land and Resources, 32(2), 2018, pp.54-60 (in Chinese).

17. Duan S. X., Liu H., "Application of AMT in detecting deep geological structures in Lejia district of Xiangshan uranium ore field". World Nuclear Geoscience, 31(3), 2014, pp.531-535 (in Chinese).

18. Wang J. Y., "Basic theory of electromagnetic array profiling method". Earth Science (Journal of China University of Geosciences), 15(s), 1990, pp.1- 10 (in Chinese). 